\title{
Short-Term and Long-Term Outcomes of Complete Mesocolic Excision with Central Vascular Ligation for Ascending Colon Cancer: Single Institution
}

Sung Woo Jang, Dae Ro Lim, Jung Chul Kuk, Tae Hyung Kim and Eung Jin Shin*

Department of Surgery, Soonchunhyang University College of Medicine, South Korea

\begin{abstract}
Purpose: The aim of the present study was to analyze the peri- and post-operative and oncologic outcomes for ascending colon cancer after complete mesocolic excision (CME) with central vessel ligation (CVL).

Materials and methods: The data of 156 patients who underwent CME with CVL for ascending colon cancer between January 2000 and December 2011 were retrieved from a prospective database.

Results: The median follow-up time was 63.6 months. The mean operation time was $191.6 \mathrm{~min}$. The mean blood loss was $85.6 \mathrm{ml}$. The mean length of the hospital stay was 13.9 days. The mean number of total harvested lymph nodes was 30.3. A 5-year cancer-specific survival (CSS) rate was seen in $83.0 \%$ of patients, and a 5-year diseasefree survival (DFS) rate was seen in $79.7 \%$. In stage I, the DFS and CSS rates were both $100 \%$. In stage II, the DFS rate was $91.0 \%$ and the CSS rate was $92.3 \%$. In stage III, the DFS rate was $53.5 \%$ and the CSS rate was $59.5 \%$. In stage IIla, the DFS and CSS rates were both $100 \%$. In stage IIIb, the DFS rate was $70.1 \%$ and the CSS rate was $92.1 \%$. In stage IIIc, the DFS rate was $19.4 \%$ and the CSS rate was $44.0 \%(p<0.01)$. The local recurrence rate was $3.8 \%$.
\end{abstract}

Conclusion: Based on the present data, CME with CVL is feasible and safe for treating ascending colon cancer. CME with CVL could lead to better oncologic outcomes for ascending colon cancer surgery.

Keywords: Ascending colon; Neoplasm; Surgery

\section{Introduction}

Colorectal cancer is the third most commonly diagnosed cancer in males worldwideand the second most commonly diagnosed cancer in females, with an estimated 1.4 million cases and 693,900 deaths occurring in 2012 [1]. Surgery is the treatment of choice for colorectal cancer [2]. The concept of total mesorectal excision (TME) provides a surgical plane of dissection and improved oncological outcomes for the treatment of rectal cancer [3-5]. In TME, the mesorectal plane is dissected to produce an intact fascial-lined specimen, which contains blood vessels, lymphatic vessels, and lymph nodes [3]. The concept of complete mesocolic excision (CME) provides a correct surgical anatomical plane for the treatment of colon cancer. In CME, the fascial space of the posterior lobe of the mesocolon is completely dissected to separate the fusion fascia from the visceral fascia and the parietal fascia up to the radix of the mesocolon [6-8]. Central vessel ligation (CVL) of the blood vessel supply to the mesocolon at the root occurs as a result of CME. CVL provides improved oncologic outcomes. In CVL, the lymph node is extensively dissected along the supply vessels $[9,10]$. Some studies reported that CME with CVL provides an increased lymph node harvest, decreased peri-operative morbidity, reduced locoregional recurrence, and improved oncologic outcomes $[11,12]$. The aim of the present study was to analyze the peri- and post-operative and long-term oncologic outcomes for ascending colon cancer after CME with CVL.

\section{Materials and Methods}

Patients ( $\mathrm{n}=156)$ who underwent CME with CVL for ascending colon adenocarcinoma between January 2000 and December 2011 were identified from a prospective database. Patients with proximal transverse colon cancer and patients who underwent multivisceral resection were excluded from the present study. Patient of stage IV were excluded from the present study. Patients were also excluded if they had synchronous, multiple, or metachronous colon cancer or hereditary colon cancer (i.e., familial adenomatous polyposis or hereditary nonpolyposis colorectal cancer). The data of all the clinical and pathological features were reviewed retrospectively. After surgery, all patients with stage II or III cancer were recommended adjuvant chemotherapy, as recommended by the National Comprehensive Cancer Network guidelines [2]. Adjuvant chemotherapy includes the use of fluoropyrimidine (i.e., fluorouracil with folinic acid and capecitabine) alone or in combination with oxaliplatin (FOLFOX). All patients underwent a colonoscopy, a biopsy, staging scans (i.e., CT scans of the chest, abdomen, and pelvis), and, occasionally, PET scans. The patients received full bowel preparation and a single shot of prophylactic antibiotics. Some reasons for not recommending, using, or continuing adjuvant chemotherapy included older ages, patient refusal, and adverse side effects. The patients received close follow-ups every 3-6 months up to 5 years after surgery, and the results of the follow-ups were recorded in a database until May 2016 or until death. Disease-free survival (DFS) was defined as the state between the date of surgery and the date of the detection of recurrence, the last follow-up, or death.

\section{Surgical procedures}

The mesenteric root up to the superior mesenteric pedicle is mobilized; dissection continues over the duodenum and the pancreatic uncinate process to allow for complete access to the superior mesenteric vein and to the medially and inferiorly located superior mesenteric

*Corresponding author: Eung Jin Shin, M.D. PhD., Professor, Section of Colon and Rectal Surgery, Department of Surgery, Soonchunghyang University Bucheon Hospital, Bucheon, South Korea, Tel: (032) 621-6267; Fax: (032) 621-6950; E-mail: colon@schmc.ac.kr

Received June 19, 2017; Accepted July 03, 2017; Published July 07, 2017

Citation: Jang SW, Lim DR, Kuk JC, Kim TH, Shin EJ (2017) Short-Term and Long-Term Outcomes of Complete Mesocolic Excision with Central Vascular Ligation for Ascending Colon Cancer: Single Institution. Surgery Curr Res 7: 299. doi: 10.4172/2161-1076.1000299

Copyright: @ 2017 Jang SW, et al. This is an open-access article distributed under the terms of the Creative Commons Attribution License, which permits unrestricted use, distribution, and reproduction in any medium, provided the original author and source are credited. 
Citation: Jang SW, Lim DR, Kuk JC, Kim TH, Shin EJ (2017) Short-Term and Long-Term Outcomes of Complete Mesocolic Excision with Central Vascular Ligation for Ascending Colon Cancer: Single Institution. Surgery Curr Res 7: 299. doi: 10.4172/2161-1076.1000299

artery. Duodenal kocherization is not performed routinely in present study. The ileocolic vessels and the right colic vessels are divided from the superior mesenteric vessels at their origin [13]; then, the ileocolic vessels are separated from the superior mesenteric artery and vein. After, ligation of the ileocolic vessels is performed, and a lateral or medial approach to shape dissection is performed along Toldt's fascia. The dissection continues medially on the mesofascial interface; then, the small intestinal mesentery, ileocecal junction, right colon, right mesocolon, and mesenteric confluence are fully mobilized from the underlying fascia and retroperitoneum and left entirely intact [14] (Figure 1)

\section{Statistical analysis}

All statistical analyses were performed using SAS Version 9.1.3 (SAS Institute Inc., Cary, NC, USA) and IBM SPSS Version 24.0 (IBM, Armonk, NY, USA). The categorical variables were analyzed using the $\chi^{2}$ or Fisher's exact test, and the continuous variables were analyzed using the student's t-test or the Mann-Whitney $\mathrm{U}$ test. Cumulative incidence methods were used to estimate the rate of cancer recurrence. The overall survival and DFS rates were analyzed using the KaplanMeier method, and a comparison of these rates was performed using the log-rank test. $P$ values of less than 0.05 were considered statistically significant. The differences in the overall survival and DFS rates were assessed using the log-rank test. A multivariate analysis of the DFS rates was performed using Cox regression.

\section{Results}

\section{Patients' characteristics}

All patients $(n=156)$ underwent an elective CME with CVL for ascending colon cancer. The mean age of the patients was $62.7 \pm$ 12.6 years. Of the 156 patients, 78 (50.0\%) were male and $78(50.0 \%)$ were female. The mean weight of the patients was $59.6 \pm 10.5 \mathrm{~kg}$ and the mean height of the patients was $159.5 \pm 9.5 \mathrm{~cm}$. The mean body mass index scores of the patients was $23.5 \pm 3.4 \mathrm{~kg} / \mathrm{m}^{2}$. In terms of the tumor location, cecal cancer occurred in 47 (30.1\%) patients, mid-

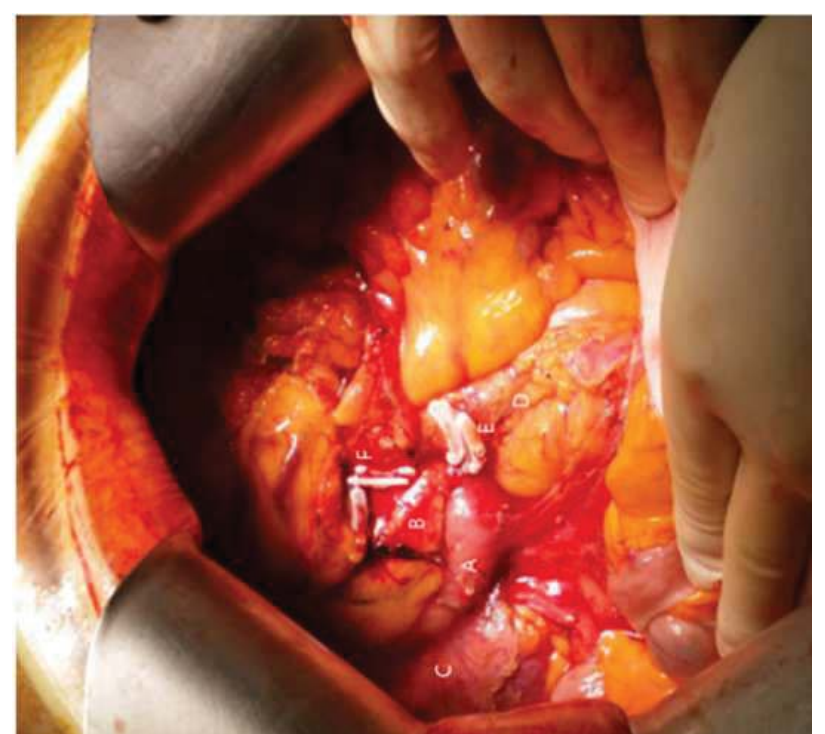

Figure 1: Complete mesocolic excision with central vessels ligation: A) 2nd portion of duodenum, B) head of pancrease, C) kidney, D) superior mesenteric vein, E) ligated ileocolic artery and vein at root along with superior mesenteric vein, $\mathrm{F}$ ) ligated right branch of middle colic artery and vein at root. ascending colon cancer occurred in $80(51.3 \%)$ patients, and hepatic flexure cancer occurred in $29(18.6 \%)$ patients. Only 10 patients $(6.0 \%)$ had a history of previous abdominal operations. In total, $116(74.4 \%)$ patients received adjuvant chemotherapy and 40 (25.6\%) did not. Open right hemicolectomy was performed in 137 (87.8\%) patients and laparoscopy-assisted right hemicolectomy was performed in 19 (12.2\%) patients. The mean initial CEA level of the patients was $22.7 \pm 79.8 \mathrm{ng} /$ $\mathrm{ml}$ (Table 1).

\section{Pathologic results}

The $\mathrm{pT}, \mathrm{pN}, \mathrm{pM}$, and tumor $(\mathrm{T})$, node $(\mathrm{N})$, and metastasis stages are outlined in Table 2 . The mean number of harvested lymph nodes was $30.3 \pm 16.9$. The mean proximal resection margin was $13.4 \pm$ $6.8 \mathrm{~cm}$, and the mean distal resection margin was $18.3 \pm 9.9 \mathrm{~cm}$. Of the patients, $3(1.9 \%)$ were in stage $0 ; 30(19.2 \%)$ were in stage I; 66 $(42.3 \%)$ were in stage IIa; 4 (2.6\%) were in stage IIb; 1 (0.6\%) was in stage IIc; 5 (3.2\%) were in stage IIIa; 29 (18.6\%) were in stage IIIb; $17(10.9 \%)$ were in stage IIIc. Of the T stages, $3(1.9 \%)$ patients were in tis; $23(14.7 \%)$ patients were in $\mathrm{T} 1 ; 13(8.3 \%)$ patients were in $\mathrm{T} 2$; $104(66.7 \%)$ patients were in T3; $10(6.4 \%)$ patients were inT4a; and 3 (1.9\%) patients were in T4b. Of the $\mathrm{N}$ stages, 104 (66.7\%) patients were in N0; $13(8.3 \%)$ patients were in N1a; $14(8.9 \%)$ patients were in $\mathrm{N} 1 \mathrm{~b} ; 7(4.5 \%)$ patients were in N2a; and $18(11.5 \%)$ patients were in N2b. Of the patients, 28 (17.9\%) had well-differentiated cancer cells, $92(59.0 \%)$ had moderately differentiated cancer cells, and $20(12.9 \%)$ had poorly differentiated cancer cells. In total, 14 (8.9\%) patients had mucinous cancer and $2(1.3 \%)$ had signet ring cell cancer. Overall, 58 (37.2\%) patients experienced lymphovascular invasion and $98(62.8 \%)$ did not. The mean proximal resection margin was $13.4 \pm 6.8 \mathrm{~cm}$ and the mean distal resection margin was $18.3 \pm 9.9 \mathrm{~cm}$. The mean tumor size was $5.7 \pm 3.1 \mathrm{~cm}$ (Table 2).

\section{Peri- and post-operative outcomes after CME with CVL}

The mean operation time of the patients was $191.6 \pm 55.9 \mathrm{~min}$. The mean blood loss was $85.6 \pm 120.3 \mathrm{ml}$. The mean hospital stay was 13.9 \pm 6.1 days. The mean time to partaking in sips of water was $4.7 \pm 2.1$

\begin{tabular}{|c|c|}
\hline & ${ }^{*} \mathrm{CME}$ with $\mathrm{CVL}(\mathrm{n}=156)$ \\
\hline Age(mean $\pm \mathrm{SD}$, (range))(year) & $62.7 \pm 12.6(28-85)$ \\
\hline \multicolumn{2}{|l|}{ Sex, $n(\%)$} \\
\hline Male & $78(50.0 \%)$ \\
\hline Female & $78(50.0 \%)$ \\
\hline BMI (mean $\pm \mathrm{SD},($ range $))\left(\mathrm{kg} / \mathrm{m}^{2}\right)$ & $23.5 \pm 3.4(16.7-33.7)$ \\
\hline \multicolumn{2}{|l|}{ ASA score, $n(\%)$} \\
\hline 1 & $58(37.2 \%)$ \\
\hline 2 & $95(60.9 \%)$ \\
\hline 3 & $3(1.9 \%)$ \\
\hline \multicolumn{2}{|l|}{ Tumor location } \\
\hline Cecum & $47(30.1 \%)$ \\
\hline Ascending colon & $80(51.3 \%)$ \\
\hline Hepatic flexure & $29(18.6 \%)$ \\
\hline Previous operation history & $10(6.0 \%)$ \\
\hline \multicolumn{2}{|l|}{ Adjuvant chemotherapy } \\
\hline Yes & $116(74.4 \%)$ \\
\hline No & $40(25.6 \%)$ \\
\hline Open & $137(87.8 \%)$ \\
\hline Laparoscopy & $19(12.2 \%)$ \\
\hline Initial CEA(mean \pm SD, (range)) $(\mathrm{ng} / \mathrm{ml})$ & $22.7 \pm 79.8(0.1-550)$ \\
\hline
\end{tabular}

Note: *CME: Complete Mesocolic Excision, CVL: Central Vascular Ligation Table 1: Patients characteristics. 
Citation: Jang SW, Lim DR, Kuk JC, Kim TH, Shin EJ (2017) Short-Term and Long-Term Outcomes of Complete Mesocolic Excision with Central Vascular Ligation for Ascending Colon Cancer: Single Institution. Surgery Curr Res 7: 299. doi: 10.4172/2161-1076.1000299

Page 3 of 6

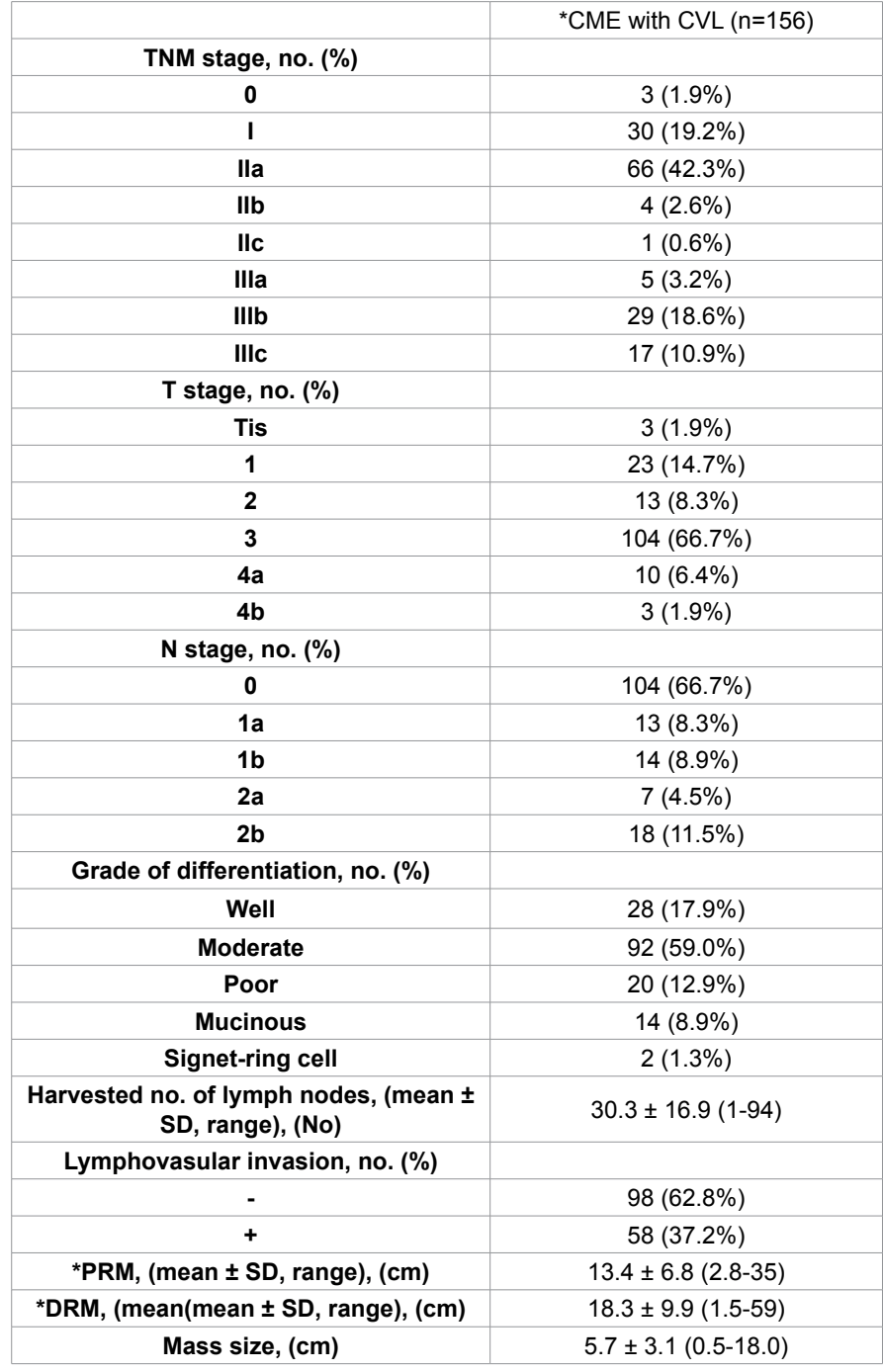

Note: *CME: Complete Mesocolic Excision, CVL: Central Vascular Ligation, PRM: Proximal Resection Margin, DRM: Distal Resection Margin

Table 2: Postoperative pathologic outcomes.

days. The mean time to partaking in a liquid diet was $6.3 \pm 2.0$ days. The mean time to partaking in a soft diet was $7.7 \pm 2.7$ days. Total number of postoperative complications was in 36 patients (23.1\%). Pulmonary problem (atelectasis, pneumonia, effusion) occurred in $3(1.9 \%)$ patients. Ileus/obstruction occurred in $15(9.6 \%)$ patients, and wound infection/dehiscence occurred in 13 (8.3\%). Postoperative bleeding occurred in $1(0.6 \%)$ patient. Inta-abdominal abscess occurred in 2 (1.3\%) patients. Chyle drainage was in $2(1.3 \%)$ patients. Anastomosis site leakage was no occurred. Post-operative mortality within 30 days occurred in $1(0.6 \%)$ patients due to postoperative massive bleeding at postoperative 4 days (Table 3 ).

\section{Oncologic outcomes}

The mean follow-up period was 63.6 months. The 5-year DFS rate was $79.7 \%$ and the 5 -year cancer-specific survival (CSS) rate was $83.0 \%$ (Figure 2). In stage I, the DFS and CSS rates were both $100 \%$. In stage II, the DFS rate was $91.0 \%$ and the CSS rate was $92.3 \%$.In stage III, the DFS rate was $53.5 \%$ and the CSS rate was $59.5 \%$. In stage IIIa, the DFS and CSS rates were both $100 \%$. In stage IIIb, the DFS rate was $70.1 \%$ and the CSS rate was $92.1 \%$. In stage IIIc, the DFS rate was $19.4 \%$ and the CSS rate was $44.0 \%(\mathrm{p}<0.01)$ (Figures 3 and 4$)$.

\begin{tabular}{|c|c|}
\hline & ${ }^{*} \mathrm{CME}$ with $\mathrm{CVL}(\mathrm{n}=156)$ \\
\hline Operation time, (min) & $191.6 \pm 55.9(100-390)$ \\
\hline Blood loss, (ml) & $85.6 \pm 120.3(50-800)$ \\
\hline Length of Hospital stay, (day) & $13.9 \pm 6.1(4-44)$ \\
\hline Time to Sips, (day) & $4.7 \pm 2.1(1-16)$ \\
\hline Time to Liquid diet, (day) & $6.3 \pm 2.0(3-19)$ \\
\hline Time to Soft diet, (day) & $7.7 \pm 2.7(4-29)$ \\
\hline Total number of complications & $36(23.1 \%)$ \\
\hline Pulmonary & $3(1.9 \%)$ \\
\hline Ileus/obstruction & $15(9.6 \%)$ \\
\hline Wound infection/dehiscence & $13(8.3 \%)$ \\
\hline Postoperative bleeding & $1(0.6 \%)$ \\
\hline Intra-abdominal abscess & $2(1.3 \%)$ \\
\hline Chyle drainage & $2(1.3 \%)$ \\
\hline Anastomosis site leakage & $0(0.0 \%)$ \\
\hline Mortality & $1(0.6 \%)$ \\
\hline
\end{tabular}

Note: *CME: Complete Mesocolic Excision, CVL: Central Vascular Ligation Table 3: Peri/postoperative outcomes after ${ }^{*} \mathrm{CME}$ with $\mathrm{CVL}$.
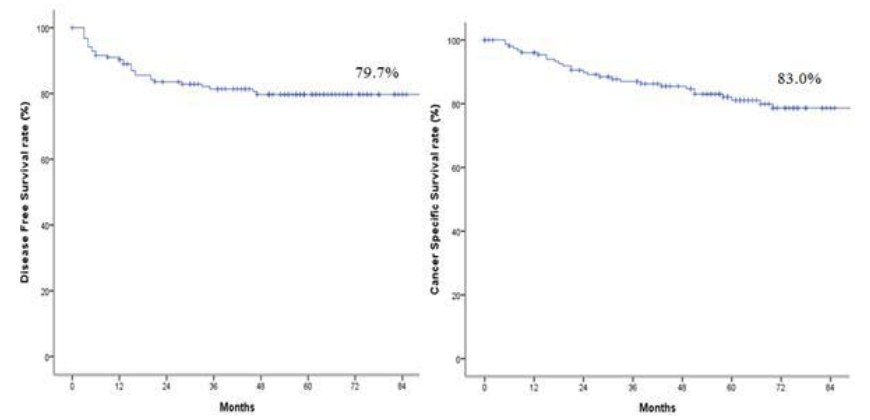

Figure 2: 5-year disease free survival rate and 5-year cancer specific survival rate after CME with CVL.

\section{Recurrence after CME with CVL}

The total number of patients who experienced recurrence was 30 (19.2\%). During the follow-up period, systemic recurrence occurred in $24(15.4 \%)$ patients and local recurrence occurred in $6(3.8 \%)$. Of the patients, $6(3.8 \%)$ experienced recurrence in the lung; $3(1.9 \%)$ experienced recurrence in the liver; $6(3.8 \%)$ experienced recurrence in the paraaortic node; $1(0.6 \%)$ experienced recurrence in the bone; and 7 (4.5\%) experienced recurrence in the peritoneum. In terms of local recurrence, $2(1.3 \%)$ patients experienced recurrence in the uterus; 1 (0.6\%) patient experienced recurrence in the ovary; $1(0.6 \%)$ patient experienced recurrence in the mesenteric lymph node; and $2(1.3 \%)$ patients experienced recurrence in the retroperitoneal lymph node (Table 4).

\section{Prognostic factors of survival after CME with CVL}

In a univariate analysis of the factors affecting survival after CME with CVL for ascending colon cancer, initial CEA level $(\mathrm{p}=0.002)$, Stage IIIc ( $\mathrm{p}=0.001)$, nodal status $(\mathrm{N} 1-2$ vs. N0; $\mathrm{P}<0.005$, N1 vs. N2; $\mathrm{p}<0.005)$, histological grade $(\mathrm{p}<0.005)$ and lymphovascular invasion $(p<0.005)$ were analyzed. However, histological grade was the only factor found to affect survival, according to the multivariate analysis $(\mathrm{p}=0.026)$ (Table 5).

\section{Discussion}

Both visceral and parietal peritoneal layers are dissected in CME. It is important to recognize that these two layers are not limited to the 
Citation: Jang SW, Lim DR, Kuk JC, Kim TH, Shin EJ (2017) Short-Term and Long-Term Outcomes of Complete Mesocolic Excision with Central Vascular Ligation for Ascending Colon Cancer: Single Institution. Surgery Curr Res 7: 299. doi: 10.4172/2161-1076.1000299
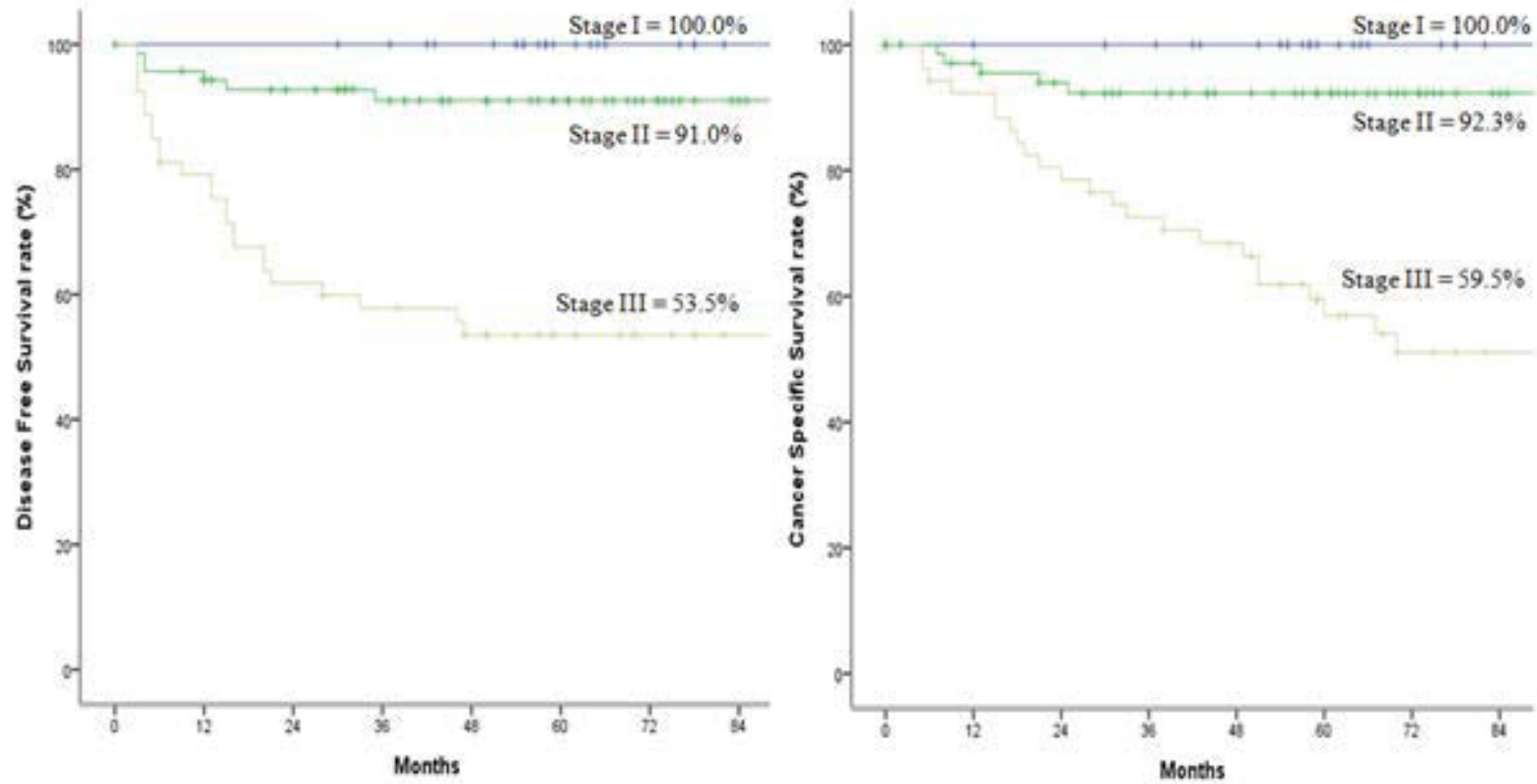

Figure 3: 5-year disease free survival rate and 5-year cancer specific survival rate according to stage.
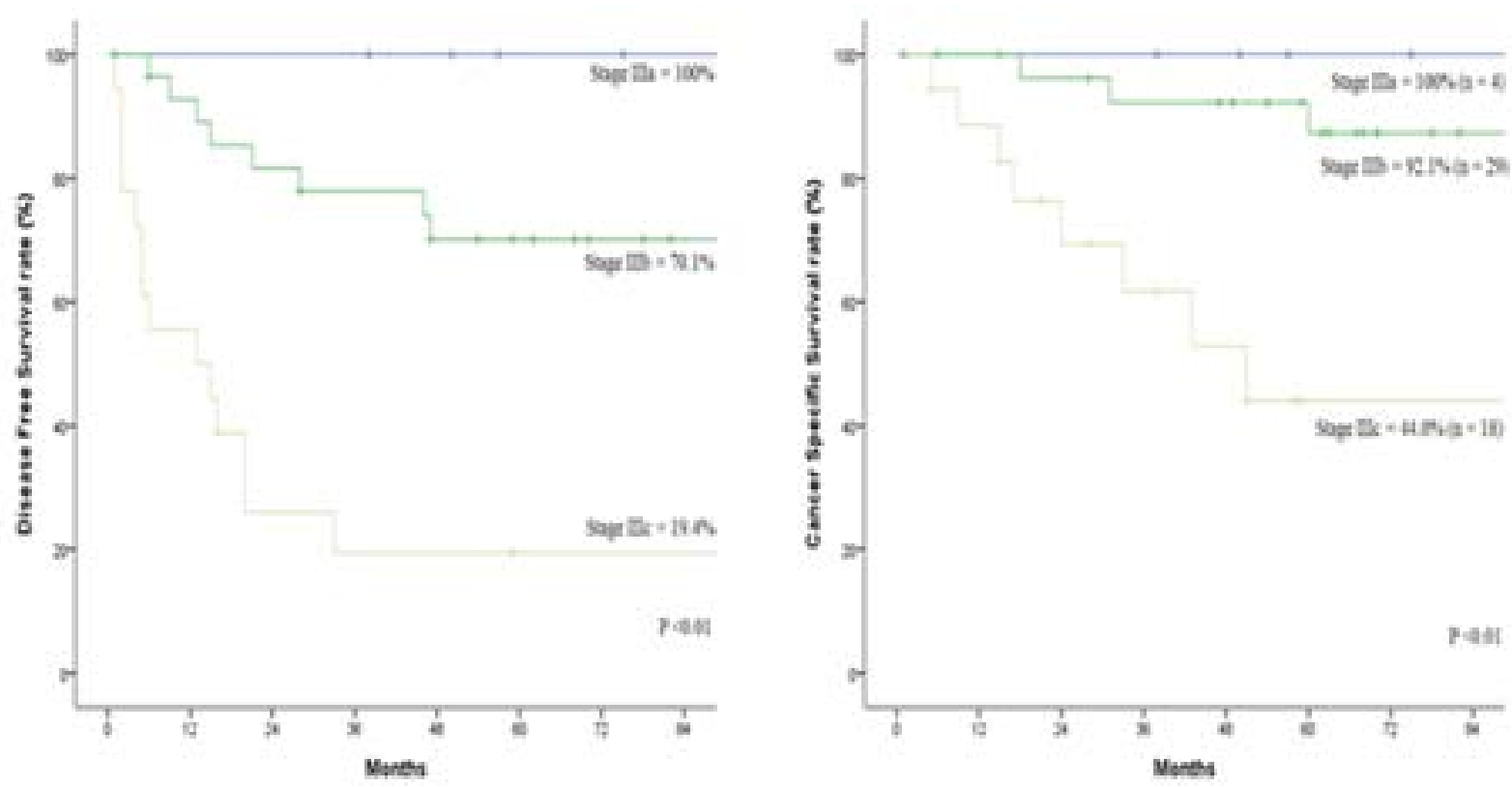

Figure 4: 5-year disease free survival rate and 5-year cancer specific survival rate according to stage III.

pelvis but cover the entire colon as a peritoneal and retroperitoneal envelope $[15,16]$. The colon is surrounded by the visceral fascia and its mesocolon, including its vessels and lymphatics; therefore, there is no lymphatic flow into the tissues of mesocolon [17]. During the en bloc resection of the colon, the fascial space in the posterior lobe of the mesocolon is completely dissected to separate the fusion fascia from the visceral fascia and the parietal fascia up to the radix of the mesocolon. The concept of and procedure for CME was initially proposed by Hohenberger et al. [6,7]. Japanese D3 dissection is based on similar methods as CME, and both techniques are oncologically superior to methods proposed by studies recently in other countries [12]. The surgical techniques of CME with CVL used in the present study were somewhat different from CME as initially described by Hohenberger et al. [6]. First, the kocherization of the duodenum was not performed routinely. Second, if tumor was not located in the hepatic flexure or the proximal transverse colon, only vessel ligation of the right side of the middle colic vessel was performed without whole ligation of middle colic vessel totally. However, most of the surgical techniques 
Citation: Jang SW, Lim DR, Kuk JC, Kim TH, Shin EJ (2017) Short-Term and Long-Term Outcomes of Complete Mesocolic Excision with Central Vascular Ligation for Ascending Colon Cancer: Single Institution. Surgery Curr Res 7: 299. doi: 10.4172/2161-1076.1000299

Page 5 of 6

\begin{tabular}{|c|c|}
\hline & \multicolumn{1}{|c|}{${ }^{*} \mathrm{CME}$ with CVL (n=156) } \\
\hline Systemic recurrence & $24(15.4 \%)$ \\
\hline Lung & $6(3.8 \%)$ \\
\hline Liver & $3(1.9 \%)$ \\
\hline Paraaortic node & $6(3.8 \%)$ \\
\hline Bone & $1(0.6 \%)$ \\
\hline Peritoneum & $1(0.6 \%)$ \\
\hline Local recurrence & $7(4.5 \%)$ \\
\hline Uterus & $6(3.8 \%)$ \\
\hline Oesenteric lymph node & $2(1.3 \%)$ \\
\hline Total Number of Recurrence & $1(0.6 \%)$ \\
\hline
\end{tabular}

Note: *CME: Complete Mesocolic Excision, CVL: Central Vascular Ligation

Table 4: Recurrence patterns after *CME with CVL.

\begin{tabular}{|c|c|c|c|c|c|c|}
\hline \multirow{2}{*}{ Factors } & \multicolumn{3}{|c|}{ Univariate analysis } & \multicolumn{3}{|c|}{ Multivariate analysis } \\
\hline & $\mathrm{HR}$ & $95 \% \mathrm{Cl}$ & P-value & $\mathrm{HR}$ & $95 \% \mathrm{Cl}$ & P-value \\
\hline Age, years (<60 vs. $\geq 60)$ & 0.6 & $0.26-1.42$ & 0.233 & & & \\
\hline Sex (Male vs. Female) & 1.28 & $0.61-2.69$ & 0.517 & & & \\
\hline BMI (<25 vs. $\geq 25$ ) & 0.98 & $0.45-2.18$ & 0.968 & & & \\
\hline Tumor location (Cecum vs. Ascending) & 0.93 & $0.54-1.59$ & 0.802 & & & \\
\hline Tumor location (Ascending vs. Hepatic flexure) & 1.37 & $0.21-1.47$ & 0.242 & & & \\
\hline Adjuvant Chemotherapy (Yes vs. No) & 3.23 & $0.77-1.36$ & 0.07 & & & \\
\hline Operation method (Open vs. Laparoscopy) & 2.68 & $0.04-1.98$ & 0.109 & & & \\
\hline CEA (< 5 vs. $\geq 5)$ & 3.2 & $1.48-6.95$ & 0.002 & 2.26 & $0.94-5.39$ & 0.067 \\
\hline Stage (IIla and IIIb vs. IIIc) & 4.46 & $2.76-7.21$ & 0.001 & 0.07 & $0.16-3.69$ & 0.075 \\
\hline Tumor invasion (T4a-b vs. T3) & 1.59 & $0.93-2.73$ & 0.06 & 1.88 & $0.15-23.79$ & 0.624 \\
\hline Lymph node metastasis & & & & 0.23 & $0.26-20.01$ & 0.269 \\
\hline (N1-2 vs. N0) & 0.13 & $0.51-0.31$ & 0 & 0.06 & $0.02-1.61$ & 0.092 \\
\hline (N1 vs. N2) & 3.93 & $2.47-6.26$ & 0 & 0.23 & $0.26-20.01$ & 0.269 \\
\hline Number of harvested lymph node $(12 \leq \mathrm{vs} .>12)$ & 0.97 & $0.34-2.81$ & 0.961 & & & \\
\hline Histological grade(Well-mod vs. others) & 7.39 & $3.39-16.04$ & 0 & 2.84 & $1.14-7.11$ & 0.026 \\
\hline Lymphovascular invasion (Present vs. absent) & 6.53 & $1.97-21.64$ & 0 & 0.25 & $0.35-1.87$ & 0.619 \\
\hline
\end{tabular}

Note: *CME: Complete Mesocolic Excision, CVL: Central Vascular Ligation, BMI: Body mass index, CEA: Carcinoembryonic antigen

Table 5: Univariate and multivariate analysis for prognostic factors of survival after ${ }^{*} \mathrm{CME}$ with $\mathrm{CVL}$ for ascending colon cancer.

and concepts used in present study were the same as those originally described by Hohenberger et al. [6].

Several previous studies reported that the rate of post-operative morbidity after CME ranges from 5.7-19.7\% [6,11,18-20]. In the present study, the total post-operative complication rate was found to be $23.1 \%$. The most commonly occurring complications were found to be ileus and wound dehiscence. The mean operation time of CME in previous studies ranged from 136-269 min, and no significant differences were reported between open and laparoscopic surgeries [21,22]. The mean operation time in the present study was found to191.6min. The means of the length of hospital stay (13.9 days), time to sips of water (4.7 days), time to soft diet (7.7 days), and blood loss $(85.6 \mathrm{ml})$ in the present study were similar to those reported in previous studies [18-21]. Specimens were collected most often from the correct anatomical plane in colon cancer resection $(92 \%$ vs. $40 \%, \mathrm{p}<0.0001)$ and had a higher number of harvested lymph nodes ( 30 vs. $18, \mathrm{p}<0.0001$ ) than non-CME specimens [7]. Several studies reported that the mean number of harvested lymph nodes in CME with CVL for right colon cancer ranged from 28-35.4 for open CME and 19-34.4 for laparoscopic CME [21-24]. The mean number of harvested lymph nodes in the present study was 30.3.

In the present study, the 5-year DFS rate was $79.7 \%$ and the 5 -year CSS rate was $83.0 \%$ with a mean follow-up of 63.6 months. The local recurrence rate was $3.8 \%$. In a systematic review of 5,246 patients with right colon cancer, the 5-year DFS rate was $77.4 \%$ and the 5 -year overall survival rate was $58.1 \%$ with a mean follow-up of 60 months. The local recurrence rate was $4.5 \%$ [25]. In the same review [25], the CME group saw more advantageous oncologic outcomes compared to the non-CME group. It is possible that the improved outcomes of CME patients are related to the resection plane and the vessel site of ligation [26]. The present study also analyzed the long-term oncologic outcomes according to the stages outlined by the 7th Edition of the American Joint Committee on Cancer. Oncologic outcomes rapidly reduced for patients in stage III compared to those in stage I or II. The oncologic outcomes for patients in stage IIIc (19.4\%, 44.0\%) were significantly lower compared to those in stage IIIa $(100 \%, 70.1 \%)$ or IIIb $(70.1 \%, 92.1 \%)(\mathrm{p}<0.01)$. The $\mathrm{T}$ stage was not found to be factors affecting survival according to the univariate and multivariate analyses conducted in the present study. However, $\mathrm{N}$ stage was found to be prognostic factor affecting survival according to the univariate analysis $[27,28]$.

\section{Conclusion}

The rate of laparoscopic surgeries performed to treat ascending colon cancer increased by $11.3 \%$ until 2011 , according to the findings 
Citation: Jang SW, Lim DR, Kuk JC, Kim TH, Shin EJ (2017) Short-Term and Long-Term Outcomes of Complete Mesocolic Excision with Central Vascular Ligation for Ascending Colon Cancer: Single Institution. Surgery Curr Res 7: 299. doi: 10.4172/2161-1076.1000299

Page 6 of 6

of the present study, and gradually increase every year. A multicenter trial (COST trial) reported that the outcomes of open and laparoscopic surgeries for colon cancer are not significantly different in terms of their 5-year overall survival rates (open: $74.6 \%$ vs. laparoscopic: $76.4 \%, \mathrm{p}=0.93$ ) and DFS rates (open: $68.4 \%$ vs. laparoscopic: $69.2 \%$, $\mathrm{p}=0.94$ ). Their local recurrence rates are also similar (open: $2.6 \%$ vs. laparoscopic: $2.3 \%, p=0.79$ ) The MRC CLASICC trial reported similar findings in terms of their 5-year overall survival rates (open: $62.7 \%$ vs. laparoscopic: $55.7 \%, \mathrm{p}=0.253$ ) and DFS rates (open: $64.0 \%$ vs. laparoscopic: $57.6 \%, \mathrm{p}=0.399$ ). Based on the data presented in this study, CME with CVL is feasible and safe for treating ascending colon cancer. Although the present study had certain limitations, like its small study population, the fact that it was a retrospective study, and the fact that the study population only included patients from a single center, CME with CVL was found to lead to better oncologic outcomes for ascending colon cancer surgery.

\section{Conflicts of Interest}

No potential conflicts of interest relevant to the present study are reported. This work was supported by Soonchunhyang University Research Fund.

\section{References}

1. Torre LA, Bray F, Siegel RL, Ferlay J, Lortet-Tieulent J, et al. (2015) Globa cancer statics, 2012. CA Cancer J Clin 65: 87-108.

2. National Comprehensive Cancer Network (2015) National Comprehensive Cancer Network Guidelines, Colon Cancer (Version 2.2015).

3. Heald RJ, Husband EM, Ryall RD (1982) The mesorectum in rectal cancer surgery-the clue to pelvic recurrence? Br J Surg 69: 613-616.

4. Enker WE (1997) Total mesorectal excision-the new golden stanfard of surgery for rectal cancer. Ann Med 29: 127-133.

5. Heald RJ, Ryall RDH (1986) Recurrence and survival after total mesorectal exicison for rectal cancer. Lancet 1: 1479-1482.

6. Hohenberger W, Weber K, Matzel K, Papadopoulos T, Merkel S (2009) Standardized surgery for colonic cancer: complete mesocolic excision and central ligation-technical notes and outcome. Colorectal Dis 11: 354-364.

7. West NP, Hohenberger W, Weber K, Perrakis A, Finan PJ, et al. (2010) Complete mesocolic excision with central vascular ligation produces an oncologically superior specimen compared with standard surgery for carcinoma of the colon. $\mathrm{J}$ Clin Oncol 28: 272-278.

8. Eiholm S, Ovesen $\mathrm{H}$ (2015) Total mesocolic excision versus traditional resection in right-sided colon cancer-method and increased lymph node harvest. Dan Med Bull 57: A4224.

9. Le Voyer TE, Sigurdson ER, Hanlon AL, Mayer RJ, Macdonald JS, et al. (2003) Colon cancer survival is associated with increasing number of lymph nodes analyzed: A secondary survey of intergroup trial INT-0089. J Clin Oncol 21: 2912-2929.

10. Chen SL, Bilchik AJ (2006) More extensive nodal dissection improves survival for stages I to III of colon cancer: A population-based study. Ann Surg 244 $602-610$

11. Kontovounisios C, Kinross J, Tan E, Brown G, Rasheed S, et al. (2015) Complete mesocolic excision in colorectal cancer: A systemic review. Colorectal Dis 17: 7-16.

12. West NP, Kobayashi H, Takahashi K, Perrakis A, Weber K, et al. (2012) Understanding optimal colonic cancer surgery: Comparison of Japanese D3 resection and European complete mesocolic excision with central vascular ligation. J Clin Oncol 30: 1763-1769.

13. Killeen S, Kessler H (2014) Complete mesocolic excision and central vesse ligation for right colon cancers. Tech Coloproctol 18: 1129-1131.

14. Coffey JC, Sehgal R, Culligan K, Dunne C, McGrath D, et al. (2014) Terminology and nomenclature in colonic surgery: Universal application of a rule-based approach derived from updates on mesenteric anatomy. Tech Coloproctol 18 789-794.

15. Frazer JE, Robbins RH (1915) On the factors concerned in causing rotation of the intestine in man. J Anat Physiol 50: 75-110.

16. Pattern BM (1968) Humman embryology (3rd edn.). McGraw-Hill, New York. p. 417.

17. Gao Z, Ye Y, Zhang W (2013) An anatomical, histopathological, and molecular biological function study of the fascias posterior to the interperitoneal colon and its associated mesocolon: Their relevance to colonic surgery. J Anat 223 123-132.

18. Cho MS, Baek SJ, Hur H, Soh Min B, Baik SH, et al. (2015) Modified complete mesocolic excision with central vascular ligation for the treatment of right-sided colon cancer: Long-term outcomes and prognostic factors. Ann Surg 261: 708715

19. Adamina M, Manwaring ML, Park KJ (2012) Laparoscopic complete mesocolic excision for right colon cancer. Surg Endosc 26: 2976-2990.

20. Kim IY, Kim BR, Choi EH, Kim YW (2016) Short-term and oncologic outcomes of laparoscopic and open complete mesocolic excision and central ligation. Int J Surg 27: 151-157.

21. Bae SU, Saklani AP, Lim DR, Kim DW, Hur H, et al. (2014) Laparoscopicassisted versus open complete mesocolic excision and central vascular ligation for right-sided colon cancer. Ann Surg Oncol 21: 2288-2294.

22. Adamina M, Manwaring ML, Park KJ, Delaney CP (2012) Laparoscopic competete mesocolic excision for right colon cancer. Surg Endosc 26: 29762990.

23. Feng B, Sun J, Ling TL, Lu AG, Wang ML, et al. (2012) Laparoscopic complete mesocolic excision (CME) with medial access for right-hemi colon cancer: Feasibility and technical strategies. Surg Endosc 26: 3669-3675.

24. Gouvas N, Pechlivanides G, Zervakis N, Kafousi M, Xynos E (2012) Complete mesocolic excision in colon cancer surgery: A comparison between open and laparoscopic approach. Colorectal Dis14: 1357-1364.

25. Killeen S, Mannion M, Devaney A, Winter DC (2014) Complete mesocolic resection and extended lymphadenectomy for colon cancer: A systematic review. Colorectal Dis 16: 577-594.

26. Hogan AM, Winter DC (2009) Complete mesocolic excision-a marker of surgical quality? J Gastrointest Surg 13: 1889-1891.

27. Fleshman J, Sargent DJ, Green E, Anvari M, Stryker SJ, et al. (2007) Laparoscopic colectomy for cancer is not inferior to open surgery based on 5-year data from the COST Study Group trial. Ann Surg 246: 655-662.

28. Jayne DG, Thorpe HC, Copeland J, Quirke P, Brown JM, et al. (2010) Five-yea follow-up of the Medical Research Council CLASICC trial of laparoscopically assisted versus open surgery for colorectal cancer. Br J Surg 97: 1638-1645. 